\title{
A Multi-Hazard Probabilistic Framework for Quantifying Bridge Failure Risk Considering Climate Change
}

\author{
Omid khandel and Mohamed Soliman* \\ School of Civil and Environmental Engineering, Oklahoma State University, Stillwater, OK
}

\begin{abstract}
Climate change has recently been recognized as a significant factor that can drive changes to current design and life-cycle assessment practices of infrastructure systems. The instability in temperature profiles and precipitation patterns in recent decades indicate that the future flood hazard occurrence rate may not necessarily follow historical trends. In addition to the impact of climate change on flood hazard occurrence rate and the associated scour progression, it could also affect the corrosion propagation in structural components. This paper presents a probabilistic framework for quantifying the multi-hazard failure risk of bridges under gradual and sudden deterioration considering climate change. Downscaled climate data adopted from the global climate models are employed to predict the future streamflow and temperature profiles at a given location. These profiles are subsequently used to quantify future failure probability and risk under corrosion and flood hazard. The proposed framework is illustrated on an existing bridge located in Oklahoma.
\end{abstract}

\section{Introduction}

Bridges are subjected to various stressors and deterioration mechanisms throughout their service life which may lead to a significant drop in the transportation system functionality. As key components in ground transportation systems, a drop in the bridge functionality can result in severe economic and social impacts. Natural hazards (e.g., floods and earthquakes) and environmental stressors (e.g., marine environments) are recognized as the main sources of bridge deterioration. The intensity and frequency of some of these events (e.g., corrosion and floods) may be related to long-term climate conditions. Therefore, climate change can considerably affect the performance of bridges under these hazards.

Scour is among the most critical hydraulic-related bridge failure mechanisms. Since most of scour effects are hidden, detecting and managing scour deterioration is generally a challenging process. Scour undermines the stability and load carrying capacity of the bridge foundations; consequently, it can lead to partial or full failure of bridges.

Over the past decades, several studies have focused on evaluating scour effects on bridges. Some of these studies where based on deterministic formulations [1,2], while others performed probabilistic analysis [3, 4]. In addition, the effect of scour on the behavior of bridges under other hazards such as seismic events or traffic overload has been investigated $[5,6]$. Several studies attempted to consider the variability of future flood hazard using return periods or through parametric investigations that assume various flood scenarios [7]; however, none of them quantified the potential effects of climate change on future flood and scour hazard occurrence using proper climate modeling.

In addition to the impact that climate change may have on flood hazard occurrence probability, it can also affect the long-term corrosion propagation rate in structural components. For instance, Stewart et al. [8,9] concluded that the long-term increase in temperatures affects the material diffusivity and consequently escalates the reinforcement corrosion rate in reinforced concrete (RC) structures. In addition, Chaves et al. [10] and Peng et al. [11] conducted probabilistic analysis on corrosion of steel in marine structures considering global warming effects. The influence of seawater temperature and microbiological nutrients on corrosion propagation was investigated in these studies. The results of both studies highlight the impact of climate change on the long-term reliability of marine structures under corrosion deterioration.

This paper presents a probabilistic framework for quantifying the effect of climate change on time dependent risk of bridge failure under flood loads, floodinduced scour, and corrosion. The proposed approach utilizes the downscaled data adopted from Global Climate Models (GCMs) to obtain future temperature and river discharge predictions under different climate scenarios. Future discharge is used to predict the scour depth and flood loads. The probability of failure under combined deterioration is computed using Monte Carlo simulation and the risk of bridge failure is quantified by combining the probability of failure and the consequences of bridge closure and/or failure. The proposed approach is applied to an existing bridge located in Oklahoma.

\footnotetext{
* Corresponding author: mohamed.soliman@okstate.edu
} 


\section{Climate modeling}

Prediction of future climate precipitation, regional moisture, temperature, and river stream flow is subjected to significant uncertainties. Accordingly, traditional structural design methods employing return periods (e.g., 50,100 or 500 year floods) may not provide accurate results. Accordingly, the proper prediction of future precipitation and temperature trends requires more advanced tools such as global climate models (GCMs). The GCMs provide a numerical representation of chemical, physical, and biological interactions of global climate system. The regional scale data should be derived from these global scale models using downscaling methods. In order to account for modelling uncertainty and climate randomness, several climate scenarios should be considered, each is characterized by its own GCM, future greenhouse gas emission scenario, and downscaling technique.

The Couple Model Inter-comparison Project Phase 5 (CMIP5) [12] presents more than 50 different GCMs that are able to project the past and future climate patterns. These models differ based on their model type and their atmospheric horizontal resolution. They also account for the interaction of natural effects such as oceans, vegetation, and land surface [13]. Uncertainty in GHG emissions can be addressed in terms of representative concentration pathways (RCPs). RCP values represent the change in the balance of radiation in Watt/meter ${ }^{2}$ between incoming solar radiation and outgoing infrared radiation from pre-industrial times to the 21 st century. RCP $2.6\left(2.6 \mathrm{~W} / \mathrm{m}^{2}\right)$, RCP $4.5\left(4.5 \mathrm{~W} / \mathrm{m}^{2}\right)$, RCP $6(6$ $\left.\mathrm{W} / \mathrm{m}^{2}\right)$, and RCP $8.5\left(8.5 \mathrm{~W} / \mathrm{m}^{2}\right)$ are the four common values. In addition, downscaling can be performed using any acceptable downscaling method such as bias correction and spatial downscaling (BCSD), constructed analogues (CA), and daily bias correction constructed analogs (BCCA) [14, 15]. The regional scale precipitation and temperature data for the time period of 1960 to 2100 with BCCA downscaling method can be adopted from Downscaled CMIP3 and CMIP5 Climate and Hydrology Projections archive [16]. Streamflow prediction at a given location should be performed using the available hydrological routing models such as variable infiltration capacity (VIC) [17] and Riverware [18] or statistical models such as IHACRES [19]. The resulting temperature and streamflow prediction profiles based on various GCMs are next used to perform corrosion and scour depth predictions, respectively.

\section{Time dependent scour prediction}

Flood-induced scour significantly affects the timevariant strength and stability of bridges subjected to flood conditions. Bed material characteristics, bed configuration, flow characteristics, fluid properties, and the geometry of the pier and footing are recognized among the factors that affect local scour at piers. In this paper, the scour depth at piers is calculated using the HEC-18 model [20].

\section{Time dependent corrosion loss}

Evaluating the long-term behavior of structures subjected to corrosive environment is highly dependent on estimating the material loss. Due to the significant uncertainties associated with the factors associated with the time-dependent corrosion loss models, predicting the residual capacity of structural components under corrosion should be performed probabilistically.

In addition, adopting historical climate records may lead to errors in characterizing the corrosion loss prediction parameters (e.g., water temperature). Therefore, the proper selection of corrosion model parameters should consider uncertainties and long-term climate change. In this paper, the immersion corrosion model presented by Melchers [21, 22] is used to predict corrosion loss in steel structures. Accordingly, the longterm effect of elevated nutrient concentration potentially arising from climate change can be quantified.

The historical water and air temperature dissolved inorganic nitrogen (DIN), and the predicted air temperature profiles from GCMs are the inputs of this corrosion prediction model. Since climate modeling only provides air temperature prediction, water temperature profiles are established based on a curve fitting technique that can draw a relationship between the air and water temperatures. In addition, distribution fitting is employed to obtain the best probability density function (PDF) which fits the DIN data adopted from USGS water data database [23]. Random DIN values are then generated through random sampling techniques to conduct the probabilistic simulation. The resulting DIN values along with the predicted future water temperature profiles are then used to estimate the y-intercept at time zero and the slope of the long-term corrosion rate of the adopted corrosion loss prediction model described by Melchers [24]. This process results in time dependent corrosion loss curves considering the annual variation of temperature due to climate change.

\section{Capacity of bridge foundations}

This paper focuses on bridges with deep pile foundations. The ultimate lateral load carrying capacity of one pile is calculated using the model proposed in Prasad and Chari [25]. The ultimate axial load carrying capacity is expressed as a sum of shaft and toe resistance of a pile. In addition to these limit states, axial buckling and yielding, as well as an elastic bending limit state, are considered in this paper.

\section{Risk assessment}

For deep pile foundations, failure will happen when axial or lateral forces exceed the foundation capacity which can be reduced due to scour formation or/and corrosive environment. In such case, the lateral and axial failure limit states can be defined based on available pile capacity models. The performance functions are then 
used to evaluate the probability of failure and risk due to flood, flood-induced scour, and corrosion. The point-intime probability of failure is calculated as

$$
P_{f}(t)=P\left[\operatorname{any} G_{i}(t)<0\right]
$$

where $P_{f}(t)$ is point-in-time probability of failure and $G_{\mathrm{i}}(t)$ is the $i$ th performance function. The system failure probability is computed as the failure probability of a system whose failure modes are connected in series. The cumulative annual probability of failure $\operatorname{TDP}\left(y_{t}\right)$, representing the cumulative distribution function of the time to failure, is computed as [26]:

$$
\operatorname{TDP}\left(y_{t}\right)=\sum_{i=1}^{t}\left\{P_{f, i} \prod_{j=1}^{i}\left(1-P_{f, j-1}\right)\right\}
$$

Finally, the time-dependent risk of structural failure, $R i s k(t)$, is calculated based on the evaluated failure probability as

$$
\operatorname{Risk}(t)=T D P\left(y_{t}\right) \times C
$$

where $C$ represents the direct and indirect consequences of failure calculated based on rebuilding cost, running cost, and time loss resulting from the bridge failure and/or road closure due to maintenance and repairs. The consequences $C$ are calculated as [26]

$$
C=C_{R 1}+C_{R 2}+C_{R 3}
$$

where $C_{R I}$ is total rebuilding cost (\$), $C_{R 2}$ is total running cost (\$), and $C_{R 3}$ representing the total cost of time loss (\$). More details on the factors associated with these cost values can be found in Stein et al [27].

\section{Illustrative example}

The presented framework is applied on an existing bridge on the south bound I-35 highway over the Red River in the United States. This bridge, located on the Oklahoma-Texas border, serves a major freight route connecting southern and northern states. The I-35 bridge superstructure consists of five steel plate girders supporting a reinforced concrete deck, while the substructure is composed of 11 piers supported by steel H-piles. The piers have two groups of 9 HP $12 \times 53$ steel H-piles, each is $11.2 \mathrm{~m}$ long. Piles are aligned such that their weak axis is parallel to the direction of streamflow. The bridge is $118.3 \mathrm{~m}$ long and $9.5 \mathrm{~m}$ wide with two traffic lanes. Each of the bridge spans is $32.3 \mathrm{~m}$ long. The thickness of the concrete deck and the width of the bridge piers are $35 \mathrm{~cm}$ and $1.2 \mathrm{~m}$, respectively. This study assumes that a failure in single pier constitutes the failure of the system.

\subsection{Temperature, flood, and scour prediction}

The downscaled climate data for MPI_ESM_LR, CCSM4, and MIROC5 global climate möels downscaled using BCCA method with RCP 2.6, RCP 4.5, and RCP 8.5 are used in this paper [16]. The resulting precipitation and temperature profiles during 1960 to 2100 time-span are adopted. The combination of three GCMs and three RCP values results in nine different scenarios. Precipitation and temperature datasets are next used in streamflow prediction and corrosion propagation models using the IHACRES model [19]. The predicted streamflow hydrographs corresponding to different climate scenarios for the location of interest are used to predict time-dependent scour.

\subsection{Time dependant corrosion loss}

The previously discussed immersion corrosion approach is applied to the bridge analyzed in this paper to quantify the increase of failure risk under corrosion. Since the investigated bridge is not located in marine environment, this corrosion model may not accurately predict the corrosion loss for the investigated location. The purpose of this study is to illustrate the application of such model in investigating the potential impacts of climate change. Other models that can predict corrosion losses in fresh water can be found in literature [28].

Historic water and temperature records are adopted from the USGS database. The curve fitting toolbox of MATLAB software [29] is next used to draw a relationship between water and air temperature data. The curve fitting result is shown in Figure 1a. Historical records of dissolved inorganic nitrogen are also adopted from USGS water quality records and their associated probabilistic distribution was obtained using MATLAB distribution fitting tool. The exponential distribution was found to provide the best fit for the DIN historical data. Figure $1 \mathrm{~b}$ shows the associated histogram and the exponential fit. The adopted temperature profiles corresponding to the nine climate scenarios are next integrated in the presented corrosion prediction approach to generate the time dependent corrosion loss considering climate change.

\subsection{Risk assessment}

In this paper, Monte Carlo simulation with 100,000 samples is used to draw samples from the time-variant corrosion rate and scour depth at the investigated bridge pier. The soil properties, streamflow data, and DIN values are treated as random variables. The probabilistic scour depth and corrosion loss are next used to quantify the time dependent probability of failure using the performance functions. After establishing the failure probability profiles, consequences due to bridge failure are evaluated considering repair cost, running cost, and time loss cost. The time dependent risk of failure is finally calculated based on the generated consequences and time dependent probability of failure. Figure 2 shows the resulting time dependent risk profiles for the investigated bridge. 

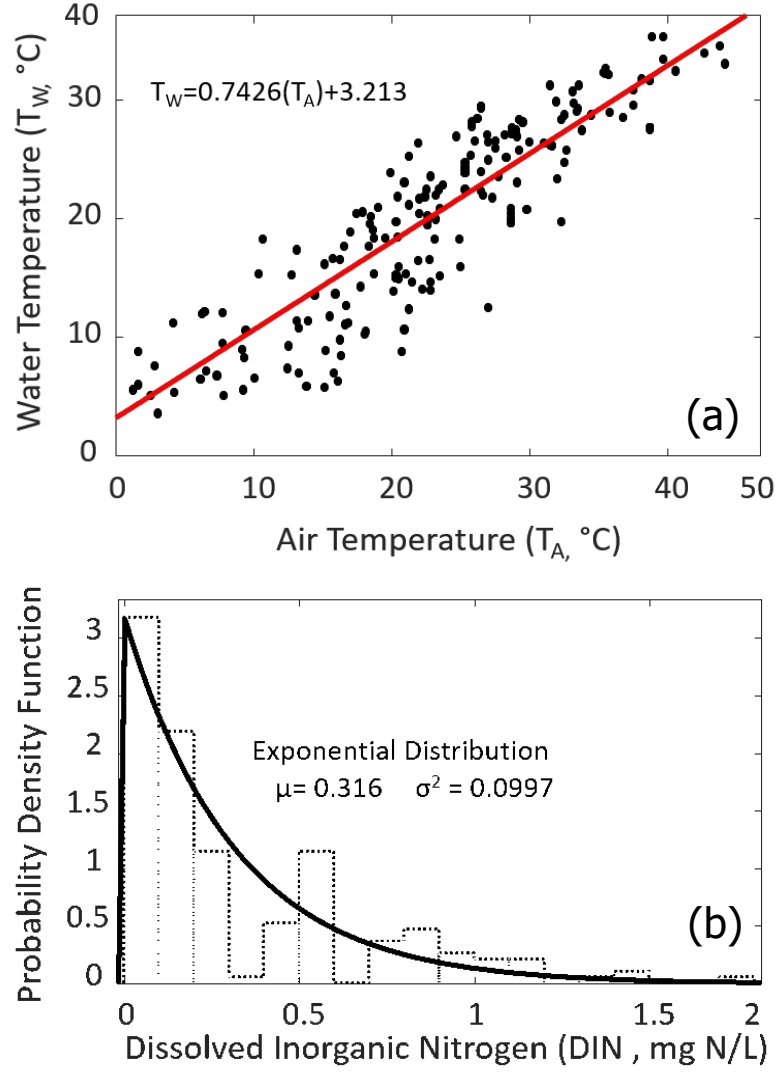

Fig. 1. (a) Air and water temperature relationship and (b) distribution fitting of DIN records.

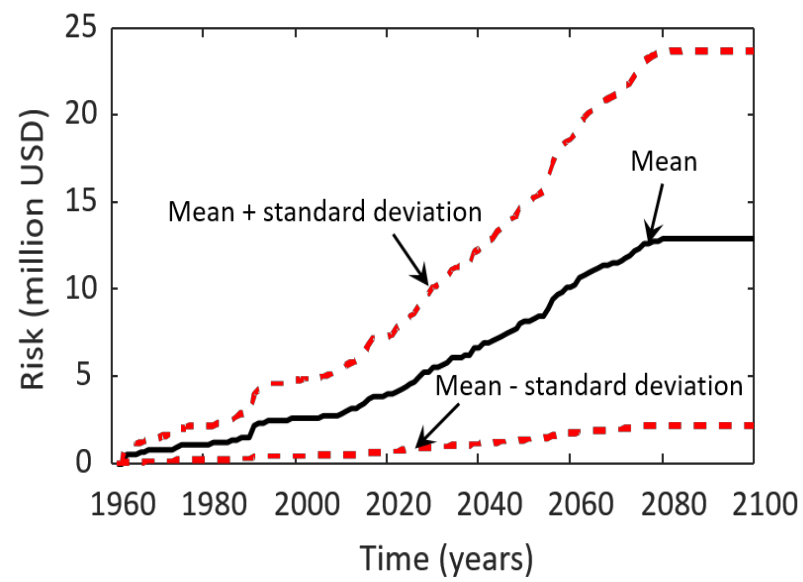

Fig. 2. Time dependent risk generated using all climate models.

\section{Conclusions}

This paper presented a probabilistic framework for risk analysis of bridges susceptible to damage due to floods, flood-induced scour, and corrosion. The proposed framework predicts the probability of failure considering the effect of climate change using downscaled data adopted from global climate models. The proposed framework can establish risk profiles which represent the time dependent performance of the structure considering climate change. The results indicate that the time-variant corrosion losses have low sensitivity to the adopted climate scenario. However, scour modelling is highly dependent on the climate model and its parameters.
Traditional methods for streamflow and corrosion loss prediction based on historic data can underestimate or over-predict the risk of bridge failure depending on the assumptions used to establish the future streamflow data. In contrast, the proposed approach based on climate modeling provides a rational prediction of future risk while properly accounting for the effect of future climate change.

The authors gratefully acknowledge the financial support from the Transportation Consortium of South-Central States (TranSET) project number 17STOKS01. The opinions and conclusions presented in this paper are those of the authors and do not necessarily reflect the views of the sponsoring organizations.

\section{References}

1. Govindasamy, A.V., Briaud, J.L, Chen, H.C., Delphia, J., Elsbury, K., Gardoni, P., Herrman, G., Kim, D., Mathewson, C.C., McClelland, M., and Olivera, F. (2008). Simplified Method for Estimating Scour at Bridges. InGeoCongress 2008: Geosustainability and Geohazard Mitigation 2008, 385-393.

2. Arneson, L.A., Zevenbergen, L.W., Lagasse, P.F., and Clopper, P.E. (2012). evaluating scour at bridges. Washington, DC: Federal Highway Administration

3. Briaud, J.L., Brandimarte, L., Wang, J., and D'Odorico, P. (2007). probability of scour depth exceedance owing to hydrologic uncertainty. Georisk. 1(2), 77-88.

4. Boldu, L.C., Gardoni, P., and Briaud, J.L. (2008). probability of exceedance estimates for scour depth around bridge piers. Journal of geotechnical and geoenvironmental engineering. 134(2), 175-84.

5. Wang, Z., Padgett, J.E., and Dueñas-Osorio, L. (2014). risk-consistent calibration of load factors for the design of reinforced concrete bridges under the combined effects of earthquake and scour hazards. Engineering Structures. 15(79), 86-95.

6. Zhu, B., Frangopol, D.M. (2016). time-dependent risk assessment of bridges based on cumulative-time failure probability. Journal of Bridge Engineering. 21(12):06016009.

7. Kallias, A.N., and Imam, B. (2016). probabilistic assessment of local scour in bridge piers under changing environmental conditions. Structure and Infrastructure Engineering. 12(9), 1228-41.

8. Stewart, M.G., Wang, X., and Nguyen, M.N. (2011). climate change impact and risks of concrete infrastructure deterioration. Engineering Structures. 33(4), 1326-1337.

9. M.G. Stewart, M.G., Wang, X., and Nguyen, M.N. (2012). climate change adaptation for corrosion control of concrete infrastructure. Structural Safety. 35:29-39.

10. Chaves, I.A., Melchers, R.E., Peng, L., and Stewart, M.G. (2016). probabilistic remaining life estimation for deteriorating steel marine infrastructure under 
global warming and nutrient pollution. Ocean Engineering. 126,129-137.

11. Peng, L., Stewart, M.G., and Melchers, R.E. (2017). corrosion and capacity prediction of marine steel infrastructure under a changing environment. Structure and Infrastructure Engineering. 13(8), 988-1001.

12. Taylor, K. E., Stouffer, R. J., \& Meehl, G. A. (2012). An overview of CMIP5 and the experiment design. Bulletin of the American Meteorological Society, 93(4), 485-498.

13. Maloney, E.D., Camargo, S.J., Chang, E., Colle, B., Fu, R., Geil, K.L., Hu, Q., Jiang, X., Johnson, N., Karnauskas, K.B., and Kinter, J. (2014). North American climate in CMIP5 experiments: Part III: Assessment of twenty-first-century projections. Journal of Climate. 27(6), 2230-70.

14. Maurer, E.P., and Hidalgo, H.G. (2008). Utility of daily vs. monthly large-scale climate data: an intercomparison of two statistical downscaling methods, Hydraulic Earth System Sciences.

15. Maurer, E.P., Hidalgo, H.G., Das, T., Dettinger, M.D., and Cayan, D.R. (2010). The utility of daily large-scale climate data in the assessment of climate change impacts on daily streamflow in California, Hydraulic Earth System Sciences.

16. Brekke, L., Thrasher, B.L., Maurer, E.P., and Pruitt, T. (2013). Downscaled CMIP3 and CMIP5 climate and hydrology projections: Release of downscaled CMIP5 climate projections, comparison with preceding information, and summary of user needs. US Dept. of the Interior, Bureau of Reclamation, Technical Services Center, Denver.

17. Liang, X., Lettenmaier, D.P., Wood, E.F., and Burges, S.J. (1994). A simple hydrologically based model of land surface water and energy fluxes for general circulation models. Journal of Geophysical Research: Atmospheres. 99(D7):14415-28.

18. Zagona, E.A., Fulp, T.J., Shane, R., Magee, T., and Goranflo, H.M. (2001). RiverWare: A generalized tool for complex reservoir system modeling. JAWRA Journal of the American Water Resources Association. 37(4), 913-929.

19. Croke, B.F., Andrews, F., Jakeman, A.J., Cuddy, S.M., Luddy, A. (2006). IHACRES Classic Plus: a redesign of the IHACRES rainfall-runoff model. Environmental Modelling \& Software. 21(3), 426-7.

20. Richardson, E.V., Harrison, L.J., Richardson, J.R., and Davis, S.R. (1993). evaluating scour at bridges. Washington, DC: Federal Highway Administration.

21. Melchers, R.E. (2003a). Modeling of marine immersion corrosion for mild and low-alloy steelsPart 1: Phenomenological model. Corrosion. 59(4), 319-34.

22. Melchers, R.E. (2003b). modeling of Marine Immersion Corrosion for Mild and Low-Alloy Steels-Part 2: Uncertainty Estimation. Corrosion. 59(4), 335-44.

23. USGS. United State Geological Survey, National Water Information Service, https://waterdata.usgs.gov/nwis. 2018.
24. Melchers, R.E. (2014). Long-term immersion corrosion of steels in seawaters with elevated nutrient concentration. Corrosion Science. 81:110-6.

25. Prasad, Y.V., and Chari, T.R. (1999). lateral capacity of model rigid piles in cohesion-less soils. Soils and Foundations. 39(2), 21-29. Parsad

26. Decò, A., and Frangopol, D.M. (2011). risk assessment of highway bridges under multiple hazards. Journal of Risk Research. 14(9), 10571089.

27. Stein, S.M., Young, G.K., Trent, R.E., and Pearson, D.R. (1999). prioritizing scour vulnerable bridges using risk. Journal of Infrastructure Systems. 5(3), 95-101.

28. European Committee for Standardization. Eurocode 3: design of steel structures - part 5: piling. 2007.

29. MathWorks, M. A. T. L. A. B. SIMULINK for technical computing. Available on http://www. rnathworks. com. 2016. 